\title{
Factors associated with the quality of life of family caregivers for leukemia patients in China
}

\author{
Hongjuan $\mathrm{Yu}^{1 \dagger}$, Limin $\mathrm{Li}^{1 \dagger}$, Chaojie $\mathrm{Liu}^{2+}$, Weidong Huang ${ }^{3 *}$, Jin Zhou ${ }^{1}$, Wenqi Fu ${ }^{3}$, Yi Ma ${ }^{3}$, Si Li ${ }^{4}$, Yuying Chang ${ }^{5}$, \\ Guoxiang $\mathrm{Liu}^{3^{*}}$ and Qunhong $\mathrm{Wu}^{3^{*}}$
}

\begin{abstract}
Background: The leukemia affects not only the quality of life (QOL) of patients with the disease but also that of their family caregivers (FCs). The research studies on QOL of FCs for leukemia patients are limited. This study aimed to evaluate the QOL of FCs for leukemia patients in Heilongjiang province, China.
\end{abstract}

Methods: A cross-sectional questionnaire survey was undertaken with 309 FCs for leukemia patients recruited from three hospitals in Heilongjiang province. The QOL of the participants was assessed using the Chinese version of WHOQOL-BREF. Multivariate regression models were established to determine the predictors of the QOL of FCs, including the socio-economic characteristics of patients and FCs, and the emotional distress, social support and family functions of FCs.

Results: The FCs had low QOL scores in all four domains: $12.7 \pm 2.8$ for physical, $12.2 \pm 2.5$ for psychological, $13.2 \pm 2.9$ for social and $11.3 \pm 2.5$ for environment. Social support is a major predictor of the QOL of FCs, with a standardized $\beta$ coefficient of "high support" ranging from 0.41 to 0.58 for the four domains, followed by family function ( $\beta=0.37 \sim 0$. 44 for psychological, social and environmental domains). The FCs who were older, highly educated, had no religious belief, suffered from a higher level of emotional distress, and provided care to younger patients and the patients without insurance coverage had lower QOL than the others.

Conclusion: The study provides some important insights into the QOL of FCs for leukemia patients. The QOL of FCs for leukemia patients is low and low levels of support to FCs are a major predictor of low QOL of FCs.

Keywords: Family caregiver, Leukemia, Quality of life, China

\section{Background}

Cancer has a significant impact not only on the patients, but also on their family caregivers (FCs) [1]. The quality of life (QOL) of FCs for cancer patients is often lower than that of those caring for patients with other chronic illnesses [2]. Previous studies found that FCs of cancer patients often experience a high level of anxiety, depression, fatigue, hopelessness, fear, guilty, regret, sleep problems, and social isolation [3-11], some of which may

\footnotetext{
*Correspondence: weidong218@126.com; lgx6301@163.com; wuqunhong@163.com

${ }^{\dagger}$ Equal contributors

${ }^{3}$ School of Health Management, Harbin Medical University, 157 Baojian Road, Nangang District, Harbin 150086, China

Full list of author information is available at the end of the article
}

not appear in those who care for patients without cancer.

FCs play a major role in how well a patient can manage his or her illness. They are often the primary source of social and emotional support for the patient [1]. The negative experience of caregivers can not only jeopardize their own QOL, but also compromise their ability to provide care [12]. The stress of FCs for patients with cancer leads to deteriorated physical health, immune function, and financial well-being, as well as psychological problems and sleep disturbances [12].

The QOL of FCs is determined by many factors, including those from the perspective of patients as well as those from the perspective of caregivers. Although some literature $[12,13]$ has reported an association 
between the QOL of FCs and the type of cancer of patients, most studies involved a sample with mixed types of cancer [14-17]. Such an approach has the advantage of increased sample size, but it may disguise potential differences in those who look after patients with different types of cancer. There is a paucity in the literature documenting cancer-specific QOL of FCs [18]. The few existing studies have focused on breast cancer, ovarian cancer, prostate cancer, and brain tumor [19-21].

This study aimed to identify factors associated with the QOL of FCs for leukemia patients in China. We chose leukemia as a focus for several reasons. First, leukemia patients have a high mortality. It is estimated that among the 352,000 people who develop leukemia every year globally, 265,000 (75.3\%) die [22]. In China, about 75,300 new cases of leukemia were diagnosed and 53,400 leukemia patients died in 2015 [23]. Among the two most common types of leukemia in China, myeloid leukemia has significantly higher levels of incidence and mortality than lymphoid leukemia [24]. An advanced stage of cancer and symptom severity has been proved to be a reliable predictor of the QOL of FCs $[4,13]$. A study in Japan demonstrated that the mothers caring for their children with leukemia have a lower QOL than the mothers caring for children without leukemia [25]. Second, the type of relationship between FCs and cancer patients has a significant influence on the commitment intensity of FCs [13]. Although leukemia occurs most often in older adults, it is also among the most common types of childhood cancer [26, 27]. This gives us a chance to examine the role of patient-FC relationships in the QOL of FCs. Previous studies [18, 25, 28] have restricted their samples to children with leukemia, including the one conducted in China [29], ignoring the fact that most leukemia patients are older adults. Although low QOL was found in FCs for children with leukemia, it is not clear whether there would be any difference for those who care for adult patients with leukemia. Third, there is a lack of study into the QOL of FCs for leukemia patients in China. A few studies undertaken outside of China have examined the QOL of FCs for patients with leukemia [18, 25, 28]. One study from Brazil with a small sample size reported low QOL of the mothers who provided care to their children with leukemia $(n=18)$ and non-Hodgkin lymphoma $(n=14)$ [18]. Another study conducted in Sri Lanka involving predominantly nuclear families showed low QOL of nearly $50 \%$ of FCs for leukemia patients in psychological, social and environmental domains [28].

In China, the traditional culture and Confucianism place a strong emphasis on the importance of family care [30-32]. It is a common practice in Chinese hospitals to require the family of a patient to arrange at least one person (either a family member or a paid care worker) to look after the patient. The duties include, but not limited to looking after personal hygiene of the patient, monitoring changes of patient conditions, keeping an eye on the progress of treatments such as $i v$ drips, and providing foods. This can partly address the problem of nurse shortages, but it imposes great burdens on patient families. Limited financial resources may further exacerbate the heavy burden of family caregivers. Cancer is often seen as a tragedy, which is likely to attract extra attention and care from family members. We anticipated an even greater impact of childhood leukemia on the parents of patients due to the decades long "one child" policy which has been in place in China since the late 1970s.

\section{Methods}

\section{Research setting}

A cross-sectional survey was conducted in three hospitals in Harbin, the capital city of Heilongjiang province. The participating hospitals were selected because they are regional centers for the treatment of leukemia in Heilongjiang province. Heilongjiang, with a population of 38.33 million, ranked in the middle range of economic development among all provinces in China, with an average GDP of $\$ 6386$ per capita in 2015 [33]. It was estimated that about 1663 patients suffer from leukemia every year in Heilongjiang [34].

\section{Data collection}

Data were collected from July 2015 to February 2016. All of the leukemia patients admitted to the participating hospitals during the survey period and their primary family caregivers (FCs) were invited to participate in this study. Primary FCs were defined as a family member who takes the major responsibility of care for the patient and commits the largest proportion of time in the care for the patient without receiving any economic retribution.

A questionnaire was administered through face-to-face interviews in a private office in the hospitals. The interviewers were recruited from research students in Harbin Medical University and trained before embarking on the survey. The interviewers identified 349 eligible FCs for this study. Of these eligible FCs, 35 expressed no interest and declined to participate.

The participating FCs were encouraged to self-complete the questionnaire. But assistance from an interviewer was always available if necessary when, for example, the respondents had a low visual acuity or another disability. The interviewers reviewed the returned questionnaires and asked the respondents to complete missing items, if any. This resulted in an over $98 \%$ completion rate: of the 314 returned questionnaires, five contained missing data (in relation to age, religious belief, duration of caregiving, and education) and 309 questionnaires without missing data were included in final analyses. 


\section{Measurements}

The QOL of the FCs was the major concern of this study. The Chinese version of WHOQOL-BREF [35], which has been validated in various populations $[15,36,37]$ was adopted to measure the QOL of the respondents. It contains 28 items, including 26 from the original version and two additional items specifically tailored to the Chinese context. The WHOQOL-BREF measures overall QOL and general health (2 items), physical health (7 items), psychological health (6 items), social relationships (3 items), and environment (8 items) using a five-point Likert scale. The item scores were added to calculate the domain scores, where a higher score indicates better QOL.

We hypothesized that the QOL of FCs is determined by the characteristics of the FCs and the patients, commitment intensity of care made by the FCs, emotional distress of the FCs, and support available to the FCs. This hypothesis was developed in line with several systematic reviews [12, 13].

We developed a questionnaire to collect data in relation to the characteristics of patients and their primary FCs. The characteristics of patients included age, sex, ethnicity, health insurance, time of diagnosis, and classification of leukemia. There are four major types of leukemia: acute lymphocytic leukemia (ALL), chronic lymphocytic leukemia (CLL), acute myelogenous leukemia (AML), and chronic myelogenous leukemia (CML). The characteristics of primary FCs included demographic characteristics (age, sex, ethnicity, marital status, employment, religion, and education), relationship to the patient, and household income.

Commitment intensity was measured by time spent per day (hours) of care while the patient stayed in the hospital and overall duration of care (months).

Emotional distress was assessed using the validated Hospital Anxiety and Depression Scale (HADS) [38], which is composed of two subscales measuring depression ( 7 items) and anxiety ( 7 items) in the prior week. Each subscale has a score ranging from 0 to 21 , with a higher score indicating a more serious condition. The condition of depression or anxiety can be categorized as normal (0-7), mild (8-10), moderate (11-14), or severe (15-21) [39].

The level of support to the FCs was assessed by social support and family function. Social support was measured using the validated Social Support Rating Scale (SSRS) [40]. The SSRS captures subjective (4 items), objective (3 Items) and the use of social support (3 items). A summed score was calculated (ranging from 0 to 66), where a higher score indicates a higher level of social support. The level of social support was categorized as low (0-22), moderate (23-44), or high (45-66) according to the SSRS designers [41] for the purpose of statistical analyses.
Family function was measured using the validated family APGAR (adaptation, partnership, growth, affection, and resolve) scale [42, 43]. The APGAR scale asked respondents to rate their satisfaction with five statements (in relation to adaptation, partnership, growth, affection, and resolve, respectively) on a 3-point scale, ranging from 0 (hardly ever) to 2 (almost always). A summed score was calculated (ranging from 0 to 10), where a higher score indicates better family functioning. The family function can be categorized as severely dysfunctional (0-3), moderately dysfunctional (4-6), or highly functional (7-10) [39].

\section{Statistical analysis}

The four domains of the WHOQOL-BREF were treated as dependent variables: physical, psychological, social relationship, and environmental.

Group comparisons on the QOL scores were made using student $t$ tests (for two groups) or one-way ANOVA tests (for multiple groups). We tested the associations of the QOL (four domains) of the FCs with the characteristics of the patients (age, sex, ethnicity, type of leukemia, duration of illness, and medical insurance coverage), the characteristics of the FCs (age, sex, ethnicity, marital status, employment, relationship to patient, level of education, understanding of patient conditions, and religious belief), household income, commitment intensity of care (total amount of time and average hours per day committed to caregiving), emotional distress, and levels of support to the FCs (family function and social support).

The variables that showed a significant association $(p<$ $0.05)$ with QOL were included in the multivariate linear regression models, with the four QOL domains serving as dependent variables. All independent variables entered into the regression models were coded or transformed into categorical measurements. We adopted an enter approach with a $p$ value less than 0.05 being deemed as statistically significant.

Data entry and statistical analyses were conducted using the Statistical Package for Social Sciences (SPSS) 22 program for Windows.

\section{Results}

The patients had a mean age of 35 years, with $24.6 \%$ being younger than 15 years. Slightly more than half (53.1\%) of the patients were female; $95.5 \%$ were Han ethnicity; $90.6 \%$ were covered by medical insurance. AML was the most common diagnosis (52.8\%), followed by ALL (31.1\%), CML (13.6\%) and CLL (2.6\%). At the time of the survey, the patients had lived with leukemia (since diagnosis) for an average of 21 months (Table 1).

Most $(54.7 \%)$ FCs were women. The majorities were parents $(44.0 \%)$ or spouses $(36.9 \%)$ of the patients, married (94.2\%), employed (77.0\%), and did not have 
Table 1 Characteristics of patients and family caregivers $(n=309)$

Characteristics
Gender ( $n$, \%)
Male
Female
Age (years, mean \pm SD)
Ethnicity
Han
Other
Types of leukemia ( $n$ \%)
ALL
AML
CLL
CML
Duration since diagnosis (Month, Mean $\pm S D$ )
Duration of caregiving (Month, Mean $\pm S D$ )
Hours of caregiveing per day(Hour, Mean $\pm S D$ )
Understand of disease ( $n$, \%)
Incompletely
Partial
Completely
Medical insurance ( $n$ \%)
Yes
No

Annual household income (Yuan)

$\begin{array}{ll}\leq 40,000 & 168(54.4 \%) \\ 40,001-79,999 & 131(42.4 \%) \\ \geq 80,000 & 10(3.2 \%) \\ \text { Relationship to patient (n, \%) } \\ \text { Spouse } \\ \text { Parent } & 114(36.9 \%) \\ \text { Child } & 136(44.0 \%) \\ \text { Other } & 43(13.9 \%) \\ \text { evel of education (n, \%) } & 16(5.2 \%) \\ \text { No more than primary school } & \\ \text { Middle or high school } & 39(12.6 \%) \\ \text { University } & 204(66.0 \%) \\ \text { Marital status (n, \%) } & 66(21.4 \%) \\ \text { Married } & \\ \text { Other } & 291(94.2 \%) \\ \text { Employment (n, \%) } & 18(5.8 \%) \\ \text { Employed } & \\ \text { Retired } & 238(77.0 \%) \\ \text { Unemployed } & 22(7.1 \%) \\ & 49(15.9 \%)\end{array}$

Table 1 Characteristics of patients and family caregivers $(n=309)$ (Continued)

\begin{tabular}{ll}
\hline Religious belief (n, \%) & $263(85.1 \%)$ \\
No & $46(14.9 \%)$ \\
Yes & $10.8 \pm 2.3$ \\
Anxiety (Mean \pm SD) & $24(7.8 \%)$ \\
Normal(n, \%) & $119(38.5 \%)$ \\
Mild(n, \%) & $149(48.2 \%)$ \\
Moderate (n, \%) & $17(5.5 \%)$ \\
Severe(n, \%) & $8.19 \pm 2.2$ \\
Depression (Mean \pm SD) & $112(36.2 \%)$ \\
Normal (n, \%) & $132(42.7 \%)$ \\
Mild (n, \%) & $65(21.0 \%)$ \\
Moderate (n, \%) & $0(0 \%)$ \\
Severe (n, \%) & $37.0 \pm 8.0$ \\
Social support (Mean $\pm S D)$ & $10(3.2 \%)$ \\
Low(n, \%) & $228(73.8 \%)$ \\
Moderate(n, \%) & $71(23.0 \%)$ \\
High(n, \%) & $6.7 \pm 1.8$ \\
Family function (APGAR score) & $8(2.6 \%)$ \\
Severely dysfunctional(n, \%) & $134(43.4 \%)$ \\
Moderately dysfunctional(n, \%) & $167(54.0 \%)$ \\
Highly functional(n, \%) & \\
\hline
\end{tabular}

religious belief (85.1\%). The household income of the FCs was low compared with the local average, with more than half (54.4\%) earning less than 40,000 Yuan a year (Table 1).

On average, the FCs had provided 15.4 months (SD = 6.9) of care for the patients. The duty of care was extremely intensive, with an average of $17.8 \mathrm{~h}(\mathrm{SD}=7.2)$ of commitments per day. Over the course, the FCs had developed a fairly good understanding about the disease. The majority of FCs admitted that they fully (35.6\%) or partially (62.1\%) understood the conditions of their patients.

The FCs experienced a high level of emotional distress, with $54 \%$ and $21 \%$ having a moderate/severe level of anxiety and depression, respectively. Slightly less than half of the families of the FCs were moderately $(43.4 \%)$ or severely (2.6\%) dysfunctional. The majority (73.8\%) of FCs received a moderate level of social support (Table 1).

The FCs of leukemia patients had low QOL scores in all four domains: $12.7 \pm 2.8$ for physical, $12.2 \pm 2.5$ for psychological, $13.2 \pm 2.9$ for social and $11.3 \pm 2.5$ for environment. These scores were significantly lower compared with those found in the general populations of a national study [44] $(p<0.001)$ (Table 2).

From the perspective of FCs, relationship to patient, depression, social support, and religious belief were found to be associated with all four domains of QOL in 
Table 2 Quality of life scores of family caregivers (Mean \pm SD)

\begin{tabular}{lllll}
\hline Domain & Family Caregivers & General population & $\mathrm{t}$ & $\mathrm{P}$ \\
\hline Physical & $12.7 \pm 2.8$ & $15.1 \pm 2.30$ & -15.09 & 0.000 \\
Psychological & $12.2 \pm 2.5$ & $13.9 \pm 1.89$ & -11.70 & 0.000 \\
Social & $13.2 \pm 2.9$ & $13.9 \pm 2.06$ & -4.60 & 0.000 \\
Environment & $11.3 \pm 2.5$ & $12.1 \pm 2.08$ & -5.95 & 0.000 \\
\hline
\end{tabular}

the univariate analyses. Those who were a parent or spouse, had no religious belief, suffered from depression, and received a lower level of social support had lower QOL. In addition, older age (>40) was associated with lower physical and social scores; lower education was associated with lower physical scores; and married FCs had a lower psychological score. Although length of caregiving was not linearly correlated with QOL scores, longer time spent on caregiving was associated with lower QOL in physical, psychological and environmental domains. Lower household income was associated with lower QOL in physical and environmental domains. A higher level of anxiety was associated with lower QOL in physical, psychological and social domains. Family dysfunction was associated with lower QOL in psychological, social and environmental domains (Table 3).

From the patient perspective, a young patient age $(<15)$ was associated with lower QOL of FCs in physical, psychological and environmental domains. ALL led to the lowest scores of FCs in physical, psychological and environmental domains among all types of leukemia. The FCs caring for patients without insurance coverage had lower scores in physical and psychological domains (Table 3).

The type of leukemia remained a predictor of QOL of FCs after controlling for other confounding factors in the multivariate models, but only for the psychological domain. CML and AML had a relatively less effect on the psychological health of FCs in comparison with ALL. Higher physical and environmental scores of FCs were found for those providing care for older patients. Patient insurance coverage showed a positive effect on the physical and psychological health of FCs (Table 4).

From the perspective of FCs, relationship to patients became insignificant in predicting the QOL of FCs in the multivariate models, although religious belief and social support remained a significant predictor of all four domains of QOL. In the regression models, social support was the biggest predictor of QOL of FCs: a high level of social support was associated with a $41-58 \%$ increase in the four domain scores compared with low support. This was followed by family function, where severe dysfunction was associated with a $37-42 \%$ decrease in the psychological, social and environmental scores of FCs. Depression was associated with lower physical and environmental scores, while anxiety was associated with lower scores of physical, psychological and social scores. Older age and higher educational attainments were also associated with lower physical scores. Marital status, household income, and duration and intensity of care commitment were insignificant for predicting QOL of FCs (Table 4).

\section{Discussion}

Increasing attention needs to be paid to the low QOL of FCs for leukemia patients

Lower QOL was found for the FCs of leukemia patients compared with the general populations in China [44]. This is consistent with the findings of other studies. A study in Japan showed that mothers caring for children with leukemia had lower scores across all eight domains of the Short Form 36, compared with mothers caring for children without leukemia [25]. Two studies of FCs for other cancer patients in China also revealed a lower QOL of FCs in comparison with the general adult populations $[45,46]$.

The low QOL of FCs deserves high attention, especially in a culture that highly values family input but has limited reliance on the social/professional care of patients $[47,48]$. In China, family members play a major role in hospital care for patients. They undertake many duties that are otherwise delivered by nurses in western countries. This is evident in this study. We found that FCs spent an average of $17.8 \mathrm{~h}$ per day providing care for leukemia patients. The importance of family support has also attracted attention from researchers in Taiwan and Korea $[49,50]$.

It is widely accepted that the relationship between FCs and the patients they care for has a profound impact on the QOL of FCs. But this study failed to establish an association between the QOL of FCs and their relationship to patients. The FCs participating in this study are predominantly (more than 80\%) parents or spouses of the patients, both having low but similar levels of QOL. However, the multivariate regression models do reveal a positive correlation between patient age and the QOL of FCs, indicating a worse QOL for those caring for young ( $<15$ years) patients. This is different from the findings of another study of cancer patients, where younger patients were found to have a better QOL, which in turn, led to a better QOL of their caregivers [51]. Such a difference may be explained by the type of cancer. Leukemia is one of the most common cancers found in children. Childhood cancer is a devastating event for a Chinese family, especially when one family has only one child [52]. Most childhood leukemia are ALL [53] and we found that the FCs providing care for ALL had the worst QOL. This result is consistent with findings of other studies $[54,55]$. In our study, $64 \%$ of the ALL patients were younger than 15 years and $98 \%$ of the child patients were cared by their parents. Although the 
Table 3 Quality of life of family caregivers measured by WHOQOL-BREF

\begin{tabular}{|c|c|c|c|c|c|}
\hline \multirow[t]{2}{*}{ Characteristics } & \multirow[t]{2}{*}{$\mathrm{n}$} & \multirow{2}{*}{$\begin{array}{l}\text { Physical } \\
\text { Mean } \pm S D\end{array}$} & \multirow{2}{*}{$\begin{array}{l}\text { Psychological } \\
\text { Mean } \pm \text { SD }\end{array}$} & \multirow{2}{*}{$\begin{array}{l}\text { Social } \\
\text { Mean } \pm S D\end{array}$} & \multirow{2}{*}{$\begin{array}{l}\text { Environment } \\
\text { Mean } \pm \text { SD }\end{array}$} \\
\hline & & & & & \\
\hline \multicolumn{6}{|l|}{ Family caregivers } \\
\hline \multicolumn{6}{|l|}{ Gender } \\
\hline Male & 140 & $12.8 \pm 2.9$ & $12.2 \pm 2.7$ & $13.3 \pm 3.1$ & $11.5 \pm 2.6$ \\
\hline Female & 169 & $12.6 \pm 2.7$ & $12.3 \pm 2.4$ & $13.1 \pm 2.8$ & $11.1 \pm 2.4$ \\
\hline \multicolumn{6}{|l|}{ Age (years) } \\
\hline$\leq 40$ & 156 & $13.1 \pm 3.1$ & $12.4 \pm 2.8$ & $13.7 \pm 3.0$ & $11.3 \pm 2.6$ \\
\hline$>40$ & 153 & $12.2 \pm 2.4$ & $12.0 \pm 2.2$ & $12.6 \pm 2.7$ & $11.2 \pm 2.4$ \\
\hline \multicolumn{6}{|l|}{ Relationship to patient } \\
\hline Spouse & 114 & $12.5 \pm 2.5$ & $11.8 \pm 2.2$ & $12.5 \pm 2.6$ & $11.1 \pm 2.2$ \\
\hline Parent & 136 & $12.1 \pm 2.6$ & $11.8 \pm 2.4$ & $13.2 \pm 2.8$ & $11.1 \pm 2.6$ \\
\hline Child & 43 & $14.6 \pm 3.1$ & $14.2 \pm 2.5$ & $14.8 \pm 3.2$ & $12.2 \pm 2.7$ \\
\hline Other & 16 & $14.0 \pm 3.4$ & $12.8 \pm 3.4$ & $13.3 \pm 3.9$ & $11.7 \pm 3.6$ \\
\hline \multicolumn{6}{|l|}{ Level of education } \\
\hline No more than primary school & 39 & $10.9 \pm 3.2$ & $11.4 \pm 2.4$ & $12.2 \pm 3.4$ & $10.5 \pm 2.5$ \\
\hline Middle or high school & 204 & $12.9 \pm 2.7$ & $12.3 \pm 2.4$ & $13.3 \pm 2.8$ & $11.3 \pm 2.5$ \\
\hline University & 66 & $13.1 \pm 2.6$ & $12.4 \pm 2.8$ & $13.2 \pm 2.9$ & $11.8 \pm 2.7$ \\
\hline \multicolumn{6}{|l|}{ Ethnicity } \\
\hline Han & 299 & $12.7 \pm 2.8$ & $12.2 \pm 2.5$ & $13.2 \pm 2.9$ & $11.3 \pm 2.6$ \\
\hline Other & 10 & $12.1 \pm 2.6$ & $11.7 \pm 2.3$ & $12.9 \pm 2.4$ & $10.8 \pm 1.6$ \\
\hline \multicolumn{6}{|l|}{ Religious belief } \\
\hline No & 263 & $12.5 \pm 2.7$ & $12.0 \pm 2.4$ & $12.9 \pm 2.8$ & $11.1 \pm 2.5$ \\
\hline Yes & 46 & $13.7 \pm 3.2$ & $13.5 \pm 2.6$ & $14.7 \pm 2.9$ & $12.1 \pm 2.5$ \\
\hline \multicolumn{6}{|l|}{ Marital status } \\
\hline Married & 291 & $12.6 \pm 2.8$ & $12.1 \pm 2.5$ & $13.1 \pm 2.9$ & $11.2 \pm 2.5$ \\
\hline Other & 18 & $13.6 \pm 2.9$ & $13.7 \pm 2.5$ & $13.7 \pm 2.5$ & $12.1 \pm 2.1$ \\
\hline \multicolumn{6}{|l|}{ Duration of caregiving (Months) } \\
\hline$\leq 6$ & 112 & $12.5 \pm 3.0$ & $12.1 \pm 2.6$ & $13.2 \pm 3.2$ & $11.3 \pm 2.7$ \\
\hline $6-12$ & 69 & $12.8 \pm 2.8$ & $12.6 \pm 2.4$ & $13.4 \pm 2.8$ & $11.5 \pm 2.2$ \\
\hline $13-24$ & 70 & $12.6 \pm 3.1$ & $11.6 \pm 2.4$ & $12.6 \pm 2.9$ & $10.8 \pm 2.5$ \\
\hline$>24$ & 58 & $12.9 \pm 2.0$ & $12.7 \pm 2.6$ & $13.4 \pm 2.5$ & $11.7 \pm 2.6$ \\
\hline \multicolumn{6}{|c|}{ Time spent caregiving per day (Hours) } \\
\hline $0-12$ & 127 & $13.1 \pm 2.9$ & $12.6 \pm 2.6$ & $13.4 \pm 3.2$ & $11.9 \pm 2.7$ \\
\hline $13-24$ & 182 & $12.4 \pm 2.7$ & $12.0 \pm 2.5$ & $13.0 \pm 2.7$ & $10.9 \pm 2.3$ \\
\hline \multicolumn{6}{|l|}{ Understanding of disease } \\
\hline Lacking & 7 & $13.1 \pm 1.1$ & $12.6 \pm 2.7$ & $13.5 \pm 2.5$ & $13.1 \pm 1.7$ \\
\hline Partial & 192 & $12.6 \pm 2.8$ & $12.2 \pm 2.3$ & $13.0 \pm 2.9$ & $11.2 \pm 2.4$ \\
\hline Fully & 110 & $12.8 \pm 3.0$ & $12.3 \pm 2.8$ & $13.4 \pm 2.9$ & $11.2 \pm 2.8$ \\
\hline \multicolumn{6}{|l|}{ Annual household income (Yuan) } \\
\hline$\leq 40,000$ & 168 & $12.2 \pm 2.9$ & $12.0 \pm 2.6$ & $13.0 \pm 2.9$ & $10.9 \pm 2.4$ \\
\hline $39,999-79,999$ & 131 & $13.1 \pm 2.7$ & $12.3 \pm 2.4$ & $13.3 \pm 2.9$ & $11.7 \pm 2.6$ \\
\hline$\geq 80,000$ & 10 & $14.0 \pm 2.7$ & $13.8 \pm 2.4$ & $13.9 \pm 3.2$ & $12.5 \pm 2.7$ \\
\hline
\end{tabular}


Table 3 Quality of life of family caregivers measured by WHOQOL-BREF (Continued)

\begin{tabular}{|c|c|c|c|c|c|}
\hline \multicolumn{6}{|l|}{ Employment } \\
\hline Employed & 238 & $12.8 \pm 2.8$ & $12.3 \pm 2.6$ & $13.3 \pm 3.0$ & $11.4 \pm 2.6$ \\
\hline Retired & 22 & $12.7 \pm 1.5$ & $11.9 \pm 1.8$ & $11.9 \pm 1.2$ & $11.4 \pm 2.0$ \\
\hline Unemployed & 49 & $12.3 \pm 3.2$ & $12.1 \pm 2.5$ & $13.0 \pm 2.9$ & $10.9 \pm 2.5$ \\
\hline \multicolumn{6}{|l|}{ Anxiety(HADS score) } \\
\hline Normal & 24 & $14.4 \pm 2.9$ & $14.2 \pm 2.7$ & $15.1 \pm 3.0$ & $12.4 \pm 3.2$ \\
\hline Mild & 119 & $13.0 \pm 2.7$ & $12.6 \pm 2.4$ & $13.7 \pm 2.8$ & $11.4 \pm 2.5$ \\
\hline Moderate & 149 & $12.2 \pm 2.7$ & $11.7 \pm 2.3$ & $12.6 \pm 2.7$ & $11.1 \pm 2.4$ \\
\hline Severe & 17 & $11.5 \pm 3.4$ & $11.5 \pm 3.1$ & $11.5 \pm 3.2$ & $10.6 \pm 2.4$ \\
\hline \multicolumn{6}{|l|}{ Depression (HADS score) } \\
\hline Normal & 112 & $13.2 \pm 2.3$ & $12.7 \pm 2.4$ & $13.7 \pm 2.8$ & $12.6 \pm 2.5$ \\
\hline Mild & 132 & $12.7 \pm 2.8$ & $12.1 \pm 2.4$ & $13.1 \pm 2.8$ & $10.9 \pm 2.2$ \\
\hline Moderate & 65 & $11.5 \pm 3.3$ & $11.6 \pm 2.7$ & $12.3 \pm 3.3$ & $9.8 \pm 2.2$ \\
\hline \multicolumn{6}{|l|}{ Social support(SSRSG score) } \\
\hline Low & 10 & $11.7 \pm 2.2$ & $9.9 \pm 1.9$ & $10.4 \pm 2.2$ & $8.9 \pm 1.6$ \\
\hline Moderate & 228 & $12.1 \pm 2.6$ & $11.7 \pm 2.3$ & $12.6 \pm 2.8$ & $10.8 \pm 2.2$ \\
\hline High & 71 & $14.8 \pm 2.4$ & $14.3 \pm 2.2$ & $15.3 \pm 2.2$ & $13.2 \pm 2.4$ \\
\hline \multicolumn{6}{|c|}{ Family function(APGAR score) } \\
\hline Severely dysfunctional & 8 & $12.3 \pm 1.9$ & $10.7 \pm 1.5$ & $11.2 \pm 2.8$ & $9.8 \pm 2.3$ \\
\hline Moderate dysfunctional & 134 & $12.3 \pm 2.9$ & $11.7 \pm 2.5$ & $12.9 \pm 3.1$ & $11.0 \pm 2.6$ \\
\hline Highly functional & 167 & $13.0 \pm 2.8$ & $12.7 \pm 2.5$ & $13.5 \pm 2.7$ & $11.6 \pm 2.4$ \\
\hline \multicolumn{6}{|l|}{ Patients } \\
\hline \multicolumn{6}{|l|}{ Gender } \\
\hline Male & 145 & $12.6 \pm 2.9$ & $12.2 \pm 2.5$ & $13.3 \pm 2.9$ & $11.1 \pm 2.5$ \\
\hline Female & 164 & $12.8 \pm 2.8$ & $12.2 \pm 2.6$ & $13.1 \pm 3.0$ & $11.4 \pm 2.5$ \\
\hline \multicolumn{6}{|l|}{ Age (years) } \\
\hline$<15$ & 75 & $11.8 \pm 2.7$ & $11.4 \pm 2.5$ & $13.4 \pm 2.6$ & $10.2 \pm 2.2$ \\
\hline$\geq 15$ & 234 & $12.9 \pm 2.8$ & $12.5 \pm 2.5$ & $13.1 \pm 3.0$ & $11.6 \pm 2.5$ \\
\hline \multicolumn{6}{|l|}{ Ethnicity } \\
\hline Han & 295 & $12.7 \pm 2.8$ & $12.3 \pm 2.5$ & $13.2 \pm 2.9$ & $11.3 \pm 2.6$ \\
\hline Other & 14 & $12.0 \pm 2.4$ & $11.1 \pm 2.4$ & $12.7 \pm 2.3$ & $10.9 \pm 1.3$ \\
\hline \multicolumn{6}{|l|}{ Types of leukemia } \\
\hline ALL & 96 & $12.2 \pm 2.7$ & $11.4 \pm 2.6$ & $13.1 \pm 3.0$ & $10.6 \pm 2.7$ \\
\hline AML & 163 & $12.7 \pm 3.0$ & $12.4 \pm 2.5$ & $13.1 \pm 2.9$ & $11.5 \pm 2.4$ \\
\hline CLL & 8 & $12.7 \pm 0.9$ & $12.6 \pm 2.1$ & $13.3 \pm 1.6$ & $11.7 \pm 1.6$ \\
\hline CML & 42 & $13.7 \pm 2.6$ & $13.2 \pm 2.2$ & $13.6 \pm 2.9$ & $11.9 \pm 2.4$ \\
\hline \multicolumn{6}{|c|}{ Duration since diagnosis (months) } \\
\hline $0-6$ & 38 & $12.8 \pm 3.1$ & $12.2 \pm 2.7$ & $13.3 \pm 3.5$ & $11.0 \pm 2.7$ \\
\hline $7-12$ & 82 & $12.9 \pm 3.2$ & $12.5 \pm 2.7$ & $13.5 \pm 3.0$ & $11.5 \pm 2.5$ \\
\hline $12-24$ & 91 & $12.8 \pm 2.7$ & $11.9 \pm 2.3$ & $12.8 \pm 2.7$ & $11.0 \pm 2.1$ \\
\hline 24 & 98 & $12.3 \pm 2.6$ & $12.3 \pm 2.5$ & $13.2 \pm 2.8$ & $11.4 \pm 2.8$ \\
\hline \multicolumn{6}{|l|}{ Medical insurance } \\
\hline Yes & 280 & $12.8 \pm 2.9$ & $12.3 \pm 2.6$ & $13.3 \pm 2.9$ & $11.3 \pm 2.6$ \\
\hline No & 29 & $11.3 \pm 2.1$ & $10.9 \pm 1.8$ & $12.3 \pm 2.5$ & $10.8 \pm 2.1$ \\
\hline
\end{tabular}

Bold indicates $P<0.05$ in group comparisons (Student's $t$ test for two groups or one-way ANOVA test for multiple groups) 
Table 4 Factors associated with quality of life of caregivers $(n=309)$

\begin{tabular}{|c|c|c|c|c|c|c|c|c|c|c|c|c|}
\hline & \multicolumn{3}{|l|}{ Physical } & \multicolumn{3}{|c|}{ Psychological } & \multicolumn{3}{|l|}{ Social } & \multicolumn{3}{|l|}{ Environment } \\
\hline & Adjusted $\beta$ & $t$ & $p$ & Adjusted $\beta$ & $t$ & $p$ & Adjusted $\beta$ & $t$ & $p$ & Adjusted $\beta$ & $t$ & $p$ \\
\hline \multicolumn{13}{|l|}{ Family Caregivers } \\
\hline Older age (vs. $\leq 40$ years) & -0.18 & -3.19 & 0.002 & & & & -0.06 & -1.22 & 0.225 & & & \\
\hline \multicolumn{13}{|l|}{ Relationship to patient(vs.others) } \\
\hline Spouse & -0.19 & -1.80 & 0.073 & -0.10 & -1.02 & 0.310 & -0.04 & -0.35 & 0.724 & -0.08 & -0.84 & 0.403 \\
\hline Parent & -0.19 & -1.70 & 0.090 & -0.06 & -0.63 & 0.531 & 0.03 & 0.28 & 0.781 & 0.09 & 0.82 & 0.416 \\
\hline Child & 0.01 & 0.14 & 0.891 & 0.12 & 1.56 & 0.119 & 0.09 & 1.19 & 0.235 & 0.00 & -0.05 & 0.963 \\
\hline \multicolumn{13}{|l|}{ Level of education(vs. $\leq$ primary school) } \\
\hline Middle or high school & 0.19 & 2.67 & 0.008 & & & & & & & & & \\
\hline University & 0.15 & 1.91 & 0.057 & & & & & & & & & \\
\hline Religious belief(vs. no belief) & 0.13 & 2.68 & 0.008 & 0.16 & 3.59 & 0.000 & 0.13 & 3.02 & 0.003 & 0.09 & 2.03 & 0.043 \\
\hline Married (vs.others) & & & & 0.07 & 1.64 & 0.101 & & & & & & \\
\hline Duration of caregiving (months) & & & & 0.07 & 1.65 & 0.100 & & & & & & \\
\hline $\begin{array}{l}13-24 \text { hours spent caregiving per day } \\
\text { (vs.0-12 hours) }\end{array}$ & 0.03 & 0.63 & 0.528 & 0.03 & 0.64 & 0.522 & & & & -0.05 & -0.99 & 0.323 \\
\hline \multicolumn{13}{|c|}{ Annual household income (vs. $\leq 40,000$ Yuan) } \\
\hline $39,999-79,999$ & 0.05 & 0.91 & 0.364 & & & & & & & 0.07 & 1.51 & 0.131 \\
\hline$\geq 80,000$ & 0.09 & 1.77 & 0.077 & & & & & & & 0.03 & 0.71 & 0.481 \\
\hline \multicolumn{13}{|l|}{ Anxiety (vs.normal) } \\
\hline Mild & -0.19 & -2.13 & 0.034 & -0.16 & -1.93 & 0.055 & -0.12 & -1.35 & 0.178 & & & \\
\hline Moderate & -0.26 & -2.78 & 0.006 & -0.27 & -3.13 & 0.002 & -0.22 & -2.54 & 0.012 & & & \\
\hline Severe & -0.15 & -2.44 & 0.015 & -0.13 & -2.33 & 0.021 & -0.17 & -2.97 & 0.003 & & & \\
\hline \multicolumn{13}{|l|}{ Depression(vs.normal) } \\
\hline Mild & -0.15 & -2.88 & 0.004 & -0.04 & -0.93 & 0.352 & -0.04 & -0.88 & 0.381 & -0.22 & -4.53 & 0.000 \\
\hline Moderate & -0.21 & -3.97 & 0.000 & 0.00 & -0.08 & 0.939 & -0.05 & -1.12 & 0.263 & -0.14 & -2.82 & 0.005 \\
\hline \multicolumn{13}{|l|}{ Family function (vs.highly functional) } \\
\hline Severely dysfunctional & & & & -0.37 & -6.30 & 0.000 & -0.44 & -7.16 & 0.000 & -0.42 & -6.95 & 0.000 \\
\hline Moderate dysfunctional & & & & -0.20 & -3.63 & 0.000 & -0.24 & -4.09 & 0.000 & -0.23 & -3.95 & 0.000 \\
\hline \multicolumn{13}{|l|}{ Social support(vs. low) } \\
\hline Moderate & 0.12 & 1.12 & 0.262 & 0.28 & 2.81 & 0.005 & 0.35 & 3.53 & 0.000 & 0.26 & 2.60 & 0.010 \\
\hline High & 0.41 & 3.74 & 0.000 & 0.52 & 5.17 & 0.000 & 0.58 & 5.60 & 0.000 & 0.51 & 4.96 & 0.000 \\
\hline \multicolumn{13}{|l|}{ Patients } \\
\hline Older patients(vs.<15) & 0.15 & 2.04 & 0.042 & 0.03 & 0.55 & 0.584 & & & & 0.19 & 3.09 & 0.002 \\
\hline \multicolumn{13}{|l|}{ Types of leukemia(vs.ALL) } \\
\hline AML & -0.02 & -0.28 & 0.778 & 0.19 & 3.15 & 0.002 & & & & 0.12 & 1.89 & 0.059 \\
\hline$C L L$ & -0.02 & -0.40 & 0.686 & 0.03 & 0.58 & 0.563 & & & & 0.00 & 0.04 & 0.966 \\
\hline$C M L$ & 0.07 & 1.18 & 0.239 & 0.14 & 2.53 & 0.012 & & & & 0.03 & 0.56 & 0.573 \\
\hline Medical insurance(vs. no insurance) & 0.11 & 2.32 & 0.021 & 0.09 & 2.21 & 0.028 & & & & & & \\
\hline$R^{2}$ & & 0.40 & & & 0.50 & & & 0.46 & & & 0.46 & \\
\hline Adjusted $R^{2}$ & & 0.36 & & & 0.46 & & & 0.43 & & & 0.43 & \\
\hline
\end{tabular}

Using a multivariate linear regression model (Enter) for significant $(p<0.05)$ variables during univariate analyses

therapeutic outcome of leukemia has improved considerably, the long duration and course of treatment, complications, and high medical bills continue to haunt many patients' families [56, 57].
Instrumental support can be essential for improving the QOL of FCs

The level of support to FCs plays a critical role in shaping the QOL of FCs for leukemia patients. Social support 
is associated with all four domains, while family function is a predictor of three domains. Family function and social support are the two biggest predictors of QOL of FCs, with a standard $\beta$ coefficient ranging from 0.37 to 0.58 . Previous studies reported social support as a significant predictor of the QOL of leukemia patients [58, 59]. But little attention has been paid to the role of social support in the QOL of FCs for cancer patients [60]. The social support obtained by the FCs in this study was already quite high, with a level comparable to the earthquake survivors who attracted national- and international-wide assistance [61]. However, it is concerning that the FCs for leukemia patients reported a high percentage (46\%) of dysfunctional families.

Financial support may be able to help ease the burden of FCs. We found that patient insurance coverage is a predictor of higher QOL of FCs, in particular in relation to their physical and psychological functioning. In a study of FCs for children with leukemia in China, Tian and colleagues [29] also found a positive correlation between household income and the QOL of FCs. Medical treatments for leukemia are expensive, which can result in financial stress on patient families. Although many care duties are dumped to FCs or paid care workers as a result of shortages of nursing workforce, the social health insurance programs in China do not cover these expenses [62]. Families with financial difficulties not only face restrictions in their choice of treatment regimes, they are also less likely to hire paid workers to alleviate the burden of caregiving $[50,63]$.

\section{Psychological and emotional support may play a limited role for improving the QOL of FCs}

Although emotional distress has been widely used for interpreting the low QOL of FCs for cancer patients $[17,64]$, this study demonstrates that it predicts some but not all of the QOL domains. Depression does not predict the psychological and social functioning of the FCs; whereas, anxiety does not predict the environmental domain of the FCs. Furthermore, the standard $\beta$ coefficients of depression and anxiety are consistently small (0.14-0.27) in the regression models, indicating a weak association with QOL.

Although only a small proportion (14.9\%) of FCs had a religious belief, those with a religious belief were found to have higher QOL. Two studies of FCs in Asian countries demonstrated a similar result $[17,50]$. It was worth noting that religion has been spreading rapidly in China in recent years [65], albeit still at a relatively low level compared to other Asian countries, such as Korea (60.8\%) [66]. Further studies are needed to tap into the role of psychological and emotional support on the QOL of FCs [60].

\section{Limitations}

This study has several limitations. As a cross-sectional survey, it is not possible to make a causal inference about the associations between the investigated factors and the QOL of FCs. The participants were recruited from one province in China. Generalization of the findings should be cautious. However, the findings on the factors associated with the QOL of FCs are unlikely to be seriously influenced by the sample selection bias. This study did not explore the relationship between patient QOL and the QOL of FCs, simply because the QOL assessment instrument selected in this study cannot be applied to children.

\section{Conclusion}

The study provides some important insights into the QOL of FCs for leukemia patients. The QOL of FCs for leukemia patients is low, which is determined by the characteristics of both patients and FCs. Low levels of support to FCs are a major predictor of low QOL of FCs. Particular attention should be paid to those who provide care to child patients and patients without insurance coverage, and those who experience family dysfunctions.

\section{Abbreviations \\ ALL: Acute lymphocytic leukemia; AML: Acute myelogenous leukemia; CLL: Chronic lymphocytic leukemia; CML: Chronic myelogenous leukemia; FCs: Family caregivers; HADS: Hospital Anxiety and Depression Scale; QOL: Quality of life; SPSS: Statistical Package for Social Sciences; SSRS: Social Support Rating Scale}

\section{Acknowledgements}

The authors are most grateful to the study participants.

\section{Funding}

This study was funded by the National Natural Scientific Foundation of China (Grant No.71503062,71603065), the Heilongjiang Postdoctoral Fund (Grant No. LBH-Z16137, LBH-Z16240), the Hospital Foundation of the First Affiliated Hospital of Harbin Medial University (Grant No. 2015B019) and the Scientific Research Foundation for Returned Overseas Chinese Scholars, Ministry of Education (Grant No.2015-311).

\section{Availability of data and materials}

The datasets generated during and/or analyzed during the current study are available from the corresponding authors on reasonable request.

\section{Authors' contributions}

$H Y, L L$ and $C L$ participated in the design of the study and revised the manuscript. WH designed the study, performed the statistical analysis and drafted the manuscript. ZJ, FW, MY, LS and CY collected and processed the data. GL collected and processed the data and helped to draft the manuscript. QW conceived of the study, and participated in its design. All authors read and approved the final manuscript.

\section{Competing interests}

The authors declare that they have no competing interests.

\section{Consent for publication}

Not applicable.

\section{Ethics approval and consent to participate}

This study was approved by the Ethics Committee of Harbin Medical University. All procedures performed in studies involving human participants were in accordance with the ethical standards of the institutional and/or 
national research committee and with the 1964 Helsinki declaration and its later amendments or comparable ethical standards.

Informed consent was obtained from all individual participants included in the study.

\section{Publisher's Note}

Springer Nature remains neutral with regard to jurisdictional claims in published maps and institutional affiliations.

\section{Author details}

'Department of Hematology, the First Affiliated Hospital of Harbin Medical University, Harbin, Heilongjiang 150001, China. ${ }^{2}$ School of Psychology and Public Health, La Trobe University, Melbourne, VIC 3086, Australia. ${ }^{3}$ School of Health Management, Harbin Medical University, 157 Baojian Road, Nangang District, Harbin 150086, China. ${ }^{4}$ Department of Hematology, the First Hospital of Harbin, Harbin, Heilongjiang 100730, China. ${ }^{5}$ Department of Hematology, the Second Affiliated Hospital of Harbin Medical University, Harbin, Heilongjiang 150081, China.

\section{Received: 9 November 2016 Accepted: 14 March 2017}

Published online: 23 March 2017

\section{References}

1. Stenberg U, Ruland CM, Miaskowski C. Review of the literature on the effects of caring for a patient with cancer. Psychooncology. 2009;19:1013-25.

2. Kim Y, Schulz R. Family caregivers' strains: comparative analysis of cancer caregiving with dementia, diabetes, and frail elderly caregiving. J Aging Health. 2008:20:483-503.

3. Romito F, Goldzweig G, Cormio C, Hagedoorn M, Andersen BL. Informal caregiving for cancer patients. Cancer. 2013;119:2160-9.

4. Kurtz M, Kurtz J, Given C, Given B. Concordance of cancer patient and caregiver symptom reports. Cancer Pract. 1995;4:185-90.

5. Sharpe L, Butow P, Smith C, McConnell D, Clarke S. The relationship between available support, unmet needs and caregiver burden in patients with advanced cancer and their carers. Psychooncology. 2005:14:102-14.

6. Nijboer C, Tempelaar R, Triemstra M, van den Bos GA, Sanderman R. The role of social and psychologic resources in caregiving of cancer patients. Cancer. 2001;91:1029-39.

7. Carter PA, Chang BL. Sleep and depression in cancer caregivers. Cancer Nurs. 2000;23:410-5.

8. Hagedoorn M, Buunk BP, Kuijer RG, Wobbes T, Sanderman R. Couples dealing with cancer: role and gender differences regarding psychological distress and quality of life. Psychooncology. 2000;9:232-42.

9. Chen $M-L$, Chu $L$, Chen H-C. Impact of cancer patients' quality of life on that of spouse caregivers. Support Care Cancer. 2004;12:469-75.

10. Nijboer C, Tempelaar R, Sanderman R, Triemstra M, Spruijt RJ, Van Den Bos GA. Cancer and caregiving: the impact on the caregiver's health. Psycho Oncol. 1998:7:3-13.

11. Huang W, Yu H, Liu C, Liu G, Wu Q, Zhou J, Zhang X, Zhao X, Shi L, Xu X. Assessing Health-Related Quality of Life of Chinese Adults in Heilongjiang Using EQ-5D-3L. 2017

12. Northouse L, Williams A, Given B, McCorkle R. Psychosocial care for family caregivers of patients with cancer. J Clin Oncol. 2012;30:1227-34.

13. Sorensen $S$, Pinquart $M$, Duberstein $P$. How effective are interventions with caregivers? An updated meta-analysis. Gerontologist. 2002;42:356-72.

14. Hacialioglu N, Özer N, Yilmaz karabulutlu E, Erdem N, Erci B. The quality of life of family caregivers of cancer patients in the East of Turkey. Eur J Oncol Nurs. 2010;14:211-7.

15. Alptekin S, Gönüllü G, Yücel I, Yarış F. Characteristics and quality of life analysis of caregivers of cancer patients. Med Oncol. 2009;27:607-17.

16. Lee YJ, Kim JE, Choi YS, Hwang IC, Hwang SW, Kim YS, Kim HM, Ahn HY, Kim SJ. Quality of life discordance between terminal cancer patients and family caregivers: a multicenter study. Support Care Cancer. 2016;24(7): 2853-60.

17. Doubova SV, Infante-Castañeda C. Factors associated with quality of life of caregivers of Mexican cancer patients. Qual Life Res. 2016;25(11):2931-40.

18. Santo EARE, Gaíva MAM, Espinosa MM, Barbosa DA, Belasco AGS. Taking care of children with cancer: evaluation of the caregivers' burden and quality of life. Rev Lat Am Enfermagem. 2011;19:515-22.
19. Northouse LL. Quality of life of women with recurrent breast cancer and their family members. J Clin Oncol. 2002;20:4050-64.

20. Awadalla AW, Ohaeri JU, Gholoum A, Khalid AOA, Hamad HMA, Jacob A. Factors associated with quality of life of outpatients with breast cancer and gynecologic cancers and their family caregivers: a controlled study. BMC Cancer. 2007;7:102

21. Chien LY, Lo LH, Chen CJ, Chen YC, Chiang CC, Yu CY. Quality of life among primary caregivers of Taiwanese children with brain tumor. Cancer Nurs. 2003;26:305-11.

22. Stewart B, Wild C. World cancer report 2014. Lyon: International Agency for Research on Cancer; 2014. p. 24-68.

23. Chen W, Zheng R, Baade PD, Zhang S, Zeng H, Bray F, Jemal A, Yu XQ, He J. Cancer statistics in China, 2015. CA Cancer J Clin. 2016:66:115-32.

24. Yuqin L, Fengju Z, Wanqing C, Lili C, Xiaodong Z, Siwei Z, Rongshou Z. An analysis of incidence and mortality of leukemia in China. China Cancer. 2009;2013:528-34

25. Yamazaki S, Sokejima S, Mizoue T, Eboshida A, Fukuhara S. Health-related quality of life of mothers of children with leukemia in Japan. Qual Life Res. 2005:14:1079-85.

26. Ram R, Wolach O, Vidal L, Gafter-Gvili A, Shpilberg O, Raanani P. Adolescents and young adults with acute lymphoblastic leukemia have a better outcome when treated with pediatric-inspired regimens: Systematic review and meta-analysis. Am J Hematol. 2012;87:472-8.

27. Kroll M, Stiller C, Richards S, Mitchell C, Carpenter L. Evidence for underdiagnosis of childhood acute lymphoblastic leukaemia in poorer communities within Great Britain. Br J Cancer. 2012:106:1556-9.

28. Pathirana TI, Goonawardena CSE, Wijesiriwardane I. Quality of life of caregivers and impact on the nuclear family of children with leukaemia in the National Cancer Institute of Sri Lanka. J Postgraduate Institute Med. 2015;2:18

29. Yanzhen $T$, Xiaohong $R$, Shuhong G, Jing C. The factors influencing quality of life in caregivers with acute leukemia children. China J Modern Med. 2012;22:100-3.

30. Kong EH. The Influence of Culture on the Experiencesof Korean, Korean American, and Caucasian - American Family Caregivers of Frail Older Adults. J Korean Acad Nurs. 2007:37:213-20.

31. Tang YY. Health promotion behaviors in Chinese family caregivers of patients with stroke. Health Promot Int. 2002;17:329-39.

32. Ge C, Yang X, Fu J, Chang Y, Wei J, Zhang F, Nutifafa AE, Wang L. Reliability and validity of the Chinese version of the Caregiver Reaction Assessment Psychiatry Clin Neurosci. 2011;65:254-63.

33. Statistics HPBo. Heilongjiang Statistical Yearbook. Peking: China Statistics Press; 2015.

34. Jie H, Wanqing C. Chinese Cancer Registry Annual Report in 2012. Peking: Military Medical Science Press; 2012.

35. Yuantao $H$, Jiqian $F$. The intruduce and usage of WHOQOL instrument in Chinese. Modern Rehabilitation. 2000:4:1127-9.

36. Li J, Lambert CE, Lambert VA. Predictors of family caregivers' burden and quality of life when providing care for a family member with schizophrenia in the People's Republic of China. Nurs Health Sci. 2007;9:192-8.

37. Yuhua R, Liping M, Peng X, Haijiang L, Lahong J, Fan L. Quality of Life of People Living with HIV/AIDS: A Cross-Sectional Study in Zhejiang Province, China. Plos One. 2015:10:e0135705

38. Leilei Z, Yeling W, Huichun L: Application of Hospital Anxiety and Depression Scale in general hospital: an analysis in reli ability and validity. Shanghai Arch Psychiatry. 2003:264-266.

39. Zuoji Z. Manual of behavioral medicine scale. Beijing: Chin Med Multimedia Press; 2005.

40. Shuiyuan $X$, Desen $Y$. The effect of social support on physical and psychological health. J Chin Psychiatry. 1987;1:183-7.

41. Xiangdong W, Xilin W, Hong M. Rating scales for mental health. Beijing: Chinese Mental Health Journal; 1999.

42. Fan L, Yuan G. the Family APGAR questionnaire and its clinical application. Foreign Med Sci. 1995;11:56-9.

43. Fan L, Guang Z, Songyuan L, Tianlun Z, Zhiqiang Z. A study on validity and reliability of the family APGAR. Chin J Public Health. 1999;15:27-8.

44. Fang J, Hao YA. Reliability and Validity for Chinese Version of WHO Quality of Life Scale. Chin Mental Health J. 1999.

45. Fangzhi Y, Jufang F, Xiuping Z, Hongmei W, Meixia W, Ling T, Miao G, Sijin G. Quality of life of family caregivers of patients with advanced cancer and its influencing factors. J Nurs. 2014;21:1-6. 
46. Suwen F, Jun L, Fang Y, Zhishu Z. Relative factors of life quality of principle caregivers of gynecologic cancer patients. Chin J Nurs. 2006;41:402-4.

47. Yueyuan L. Needs and social support aof leukemia patients and their family analysis study. China Youth University for Political Sciences, 2014.

48. Yuling $L$. The correlation between family functioning and quality of life in the parents of children with acute leukemia. Today Nurse. 2013:4-6.

49. Yeh PM, Wierenga ME, Yuan SC. Influences of psychological well-being, quality of caregiver-patient relationship, and family support on the health of family caregivers for cancer patients in Taiwan. Asian Nurs Res. 2009;3:154-66.

50. Son KY, Lee CH, Park SM, Lee CH, Oh SI, Oh B, Tak SH, Cho B, Lee K, Lee SH. The factors associated with the quality of life of the spouse caregivers of patients with cancer: a cross-sectional study. J Palliat Med. 2012;15:216-24.

51. Shahi V, Lapid MI, Kung S, Atherton PJ, Sloan JA, Clark MM, Rummans TA. Do age and quality of life of patients with cancer influence quality of life of the caregiver? J Geriatric Oncol. 2014:5:331-6.

52. Liping C, Ziqiang $X$. A study of family function and its related factors. Exploration Psychol. 2001;21:55-60.

53. Pulte $\mathrm{D}$, Gondos A, Brenner $\mathrm{H}$. Improvement in survival in younger patients with acute lymphoblastic leukemia from the 1980 s to the early 21 st century. Blood. 2009;113:1408-11.

54. Klassen AF, Klaassen R, Dix D, Pritchard S, Yanofsky R, O'Donnell M, Scott A Sung L. Impact of caring for a child with cancer on parents' health-related quality of life. J Clin Oncol Off J Am Soc Clin Oncol. 2008;26:5884-9.

55. Iqbal A, Siddiqui KS. Depression among parents of children with acute lymphoblastic leukemia. J Ayub Med College Abbottabad Jamc. 2001;14:6-9.

56. Bin L. A correlation study on acute leukemia children's parents' mental elasticity, social support and life quality. Zhengzhou University, 2015.

57. Curran E, Stock W. How I treat acute lymphoblastic leukemia in older adolescents and young adults. Blood. 2015;125:3702-10.

58. Yingchun M, Xiaojing D, Juying T, Qiaoling Q, Lili D. Relative research between social support and quality of life for leukemia patients. Chin J Modern Nurs. 2009;15:313-5.

59. Ping $H$, Liqun $C$. the relationship social support and quality of life of patients with leukemia Chin J Nurs. 2005:65-67.

60. Choi YS, Hwang SW, Hwang IC, Lee YJ, Kim YS, Kim HM, Youn CH, Ahn HY, Koh S-J. Factors associated with quality of life among family caregivers of terminally ill cancer patients. Psychooncology. 2016;25:217-24.

61. Ke X, Liu C, Li N. Social support and Quality of Life: a cross-sectional study on survivors eight months after the 2008 Wenchuan earthquake. BMC Public Health. 2009;10:2359-68.

62. Chen Z, Hongying $P$, Ji Z, Mengmeng $H$, Wenwen M, Ting Z. The current situation of foreign long-term care insurance and enlightenment to China's elder care service. J Nurs Sci. 2015;30:95-8.

63. Bugge $\mathrm{C}$, Alexander $\mathrm{H}$, Hagen S. Stroke patients' informal caregivers patient, caregiver, and service factors that affect caregiver strain. Stroke. 1999;30: 1517-23.

64. Grov EK. Anxiety, depression, and quality of life in caregivers of patients with cancer in late palliative phase. Ann Oncol. 2005;16:1185-91.

65. Yufang D. Cuttent situation and develepment trend of religions in contemporary China. J Central Institute of Socialism. 2010:77-83.

66. Yunfeng $L$. Report on contemporary Chinese religious based on data of CFPS(2012). World Religious Cultures 2014:11-25

\section{Submit your next manuscript to BioMed Central and we will help you at every step:}

- We accept pre-submission inquiries

- Our selector tool helps you to find the most relevant journal

- We provide round the clock customer support

- Convenient online submission

- Thorough peer review

- Inclusion in PubMed and all major indexing services

- Maximum visibility for your research

Submit your manuscript at www.biomedcentral.com/submit

) Biomed Central 